\title{
Treatment of Imipramine-Induced Dyspigmentation with Q-Switched Alexandrite Laser Therapy
}

\author{
Jeffrey S. Orringer, MD, ${ }^{*}$ Lori Lowe, MD, ${ }^{* \dagger}$ and Kelly B. Cha, MD*
}

The authors have indicated no significant interest with commercial supporters.

$\mathrm{T}$ he development of blue or gray cutaneous hyperpigmentation is a rare complication of chronic imipramine therapy. ${ }^{1,2}$ Treatment options for imipramine-induced hyperpigmentation are limited but include topical retinoids, bleaching agents, and laser therapy, with varying degrees of success. ${ }^{3}$ We report a case in which Q-switched alexandrite laser therapy alone led to nearly complete resolution of imipramine-induced dyspigmentation in a patient who had been taking this medication for 4 decades. Paradoxical darkening of imipramine-induced hyperpigmentation after combined Q-switched neodymium-doped yttrium aluminum garnet (Nd:YAG) and Q-switched ruby laser therapy has recently been demonstrated. ${ }^{4}$ Here, we further report a similar pattern of focal paradoxical hyperpigmentation after treatment of imipramine-induced hyperpigmentation with Q-switched alexandrite laser therapy that resolved with additional treatment sessions.

Hyperpigmentation is a rare side effect of chronic tricyclic antidepressant use characterized by progressive blue or slate-gray dyspigmentation primarily affecting sun-exposed sites. Complexes of melanin with a drug metabolite are found within dermal macrophages and free in the dermis. ${ }^{1}$ Dyspigmentation may resolve spontaneously if the offending medication is withdrawn. There is a single previous case report of successful treatment of imipramine-induced dyspigmentation with a combination of therapies including carbon dioxide and erbium YAG (Er:YAG) laser resurfacing, topical hydroquinone, a topical retinoid, topical vitamin $\mathrm{C}$ serum, and Q-switched ruby and alexandrite lasers. ${ }^{3}$ In addition, Izikson and Anderson recently reported paradoxical darkening after combined Q-switched Nd:YAG and ruby laser therapy in another patient with imipramine-induced hyperpigmentation. ${ }^{4}$

\section{Case Report}

A 66-year-old woman presented to our laser clinic with a 4- to 5-year history of progressive blue-brown discoloration of her face and neck and the dorsal surfaces of her hands (Figure 1). She has a history of depression for which she had taken imipramine daily for 40 years, and she noticed the discoloration soon after initiating hormone replacement therapy (HRT) for menopausal symptoms. She discontinued HRT but was unwilling to consider discontinuing imipramine, and the dyspigmentation gradually progressed, ultimately leading to social withdrawal. On physical examination, she had diffuse, striking, macular blue-brown to purple hyperpigmentation of her face, neck, and upper chest, with less-pronounced involvement of the dorsal hands. A biopsy was performed at her lateral neck, demonstrating golden-brown pigmented material within tissue macrophages and free in the dermis consistent with medication-induced hyperpigmentation (Figure 2). 


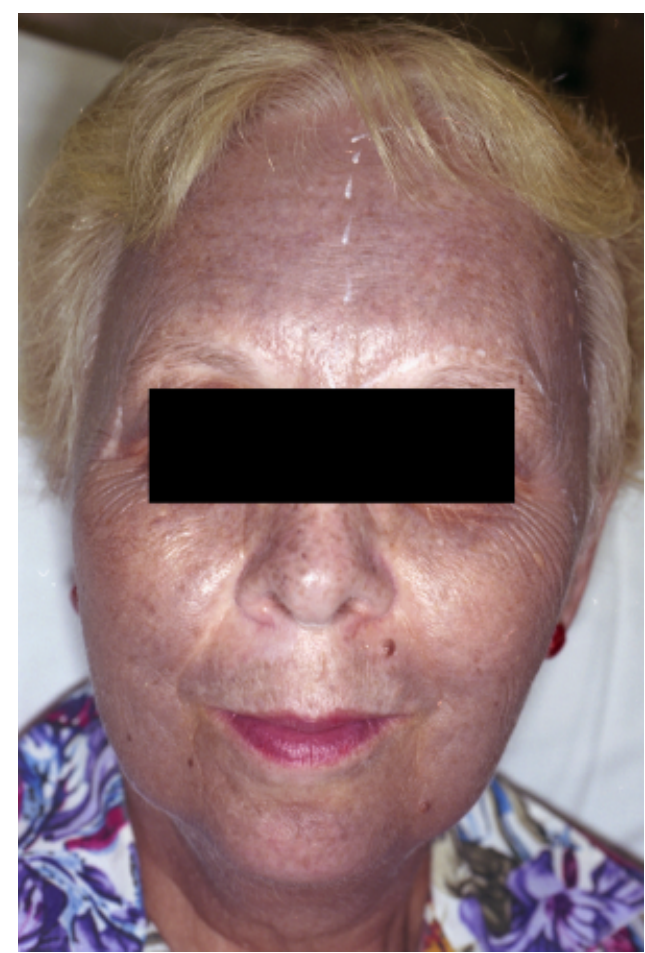

Figure 1. Preoperative appearance of the patient's facial skin demonstrating marked blue-brown hyperpigmentation.

Initial test spot laser treatments of right-sided preauricular skin performed with Q-switched Nd:YAG, Q-switched frequency-doubled Nd:YAG,

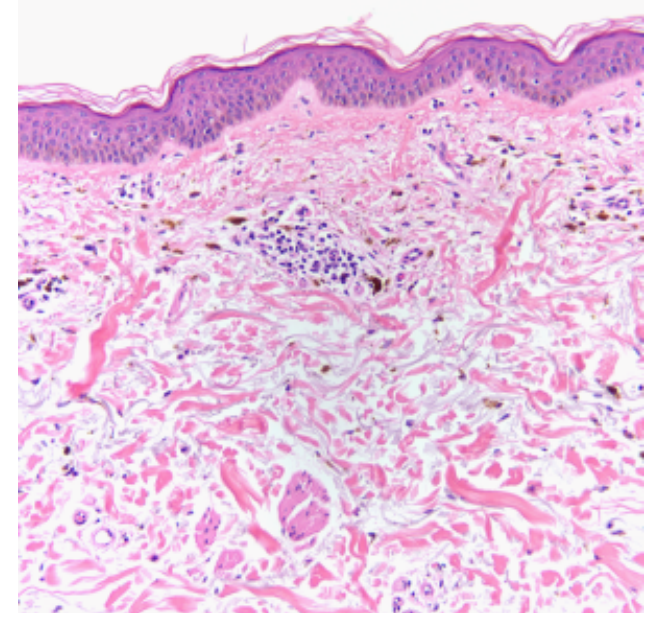

Figure 2. Sections demonstrate an unremarkable epidermis. In the superficial and mid-dermis are small collections of golden-brown pigmented material within tissue macrophages and free in the dermis. The pigmentary deposits are consistent with drug-induced pigmentation. and Q-switched alexandrite lasers demonstrated the most significant improvement with the last.

Quadrants of the patient's facial skin and neck were subsequently treated with the Q-switched alexandrite laser (spot size $2-3 \mathrm{~mm}$, fluence $8-10 \mathrm{~J} / \mathrm{cm}^{2}$ ) on four occasions over a 6-month period, with marked clearing of treated skin (Figure 3). After three treatments, several dark blue macules measuring 2 to $3 \mathrm{~mm}$ in diameter were noted in focal areas along the left jaw line and temple. The sites of paradoxical darkening resolved after treatment with additional Q-switched alexandrite laser therapy. The patient is currently scheduled to undergo similar treatment of the affected areas of her hands. After clinical resolution of the hyperpigmentation, our patient's psychological status improved substantially, and she and her husband report that she has been able to return to her normal social activities (Figure 4). Given our patient's resistance to discontinuing imipramine, she will probably require further laser treatments in the future to maintain the striking

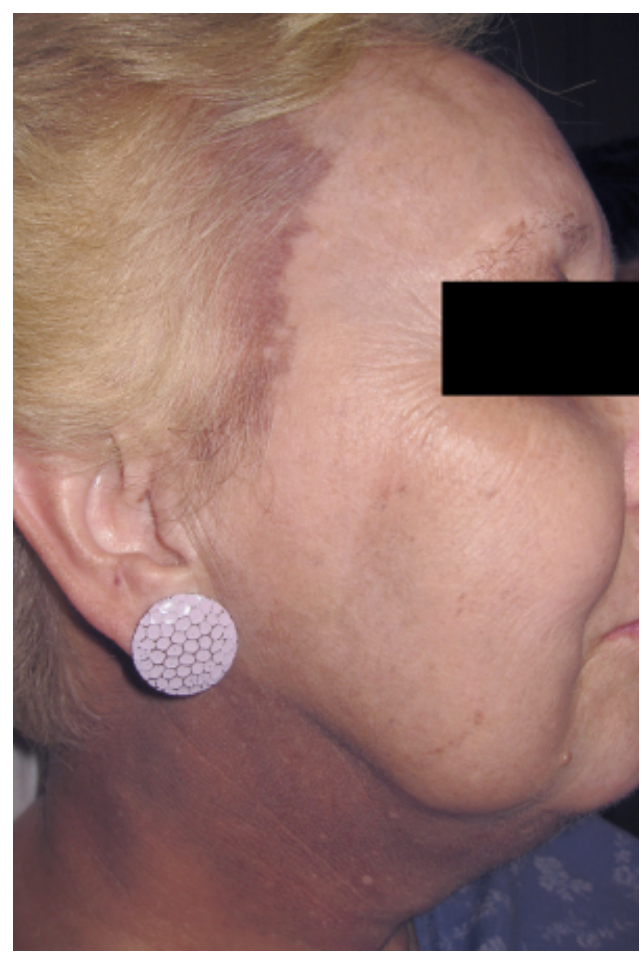

Figure 3. Clinical improvement with clearance of pigmentation on the right side of the face. Note the contrast between the patient's normal skin color and that of untreated skin on the right side of the neck and at the hairline. 


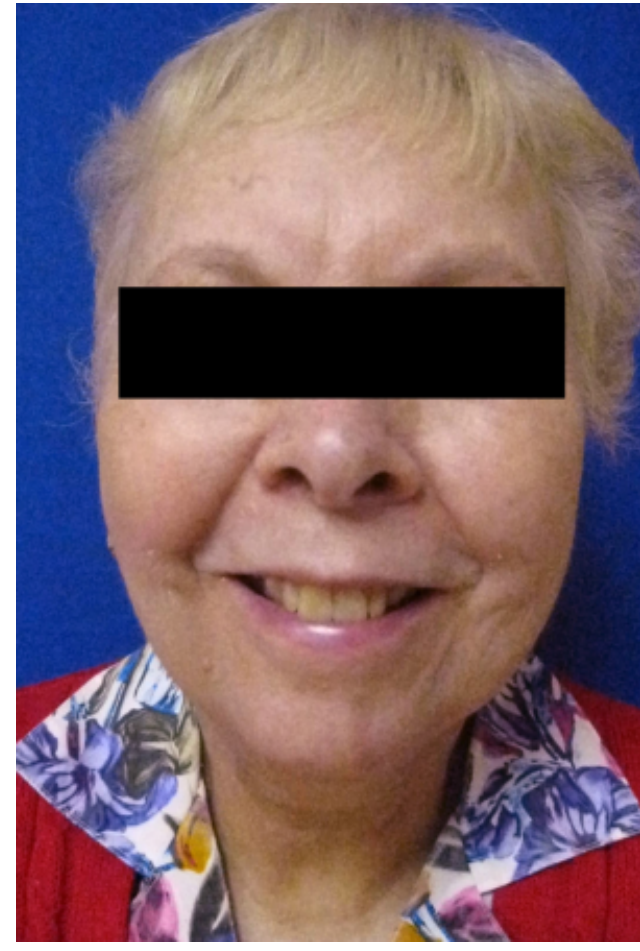

Figure 4. Near-complete resolution of imipramine-induced dyspigmentation.

improvement already seen, but there has been no recurrent dyspigmentation of the face for 1 year.

\section{Discussion}

A variety of medications may produce cutaneous dyspigmentation. The successful use of Q-switched laser therapy has been reported in the treatment of drug-induced hyperpigmentation from the use of minocycline, amiodarone, phenothiazines, and tricyclic antidepressants. ${ }^{5-7}$ Clearance of imipramine-induced hyperpigmentation using Q-switched alexandrite laser treatments as monotherapy has not previously been described. Our patient had a marked response to this laser therapy despite the fact that she remained on imipramine throughout her treatment series and had taken this medication for approximately 40 years. We believe that this is the longest duration of drug use in the fewer than 20 cases of imipramine-induced hyperpigmentation reported in the literature.
Although the precise etiology of imipramine-induced hyperpigmentation is not known, drug metabolites are believed to deposit in the skin, possibly complexed with melanin. The obvious photodistribution of our patient's hyperpigmentation supports the theory of photoactivation of the imipramine metabolites in producing the clinically apparent dyspigmentation. The 755-nm-wavelength Q-switched alexandrite laser may provide optimal correction of imipramine-induced hyperpigmentation not only because the melanin-drug metabolite complex is a chromophore for light of this wavelength, but also because the alexandrite laser produces light that penetrates well into the dermis, where even deeply located pigment may be selectively targeted.

Finally, although our patient experienced focal areas of paradoxical macular darkening soon after beginning her treatment series, this responded completely to additional Q-switched alexandrite laser therapy using slightly higher fluences. The cause of this phenomenon is unclear, but we can speculate that the initial laser treatments chemically altered but did not destroy the pigment and that subsequent exposure to higher-fluence laser energy may have resulted in complete photothermolysis. Given that there was no paradoxical darkening in more than $99 \%$ of the treated skin's surface area, we would propose that treating physicians observe for this phenomenon but that the possibility of its occurrence is not a contraindication to the use of this device. We believe that Q-switched alexandrite laser therapy may currently be considered the treatment of choice for imipramine-induced hyperpigmentation.

Acknowledgments This study was supported by the University of Michigan Department of Dermatology Laser Research Fund.

\section{References}

1. D’Agostino ML, Risser J, Robinson-Bostom L. Imipramineinduced hyperpigmentation: a case report and review of the literature. J Cutan Pathol 2009;36:799-803. 
2. Ming ME, Bhawan J, Stefanato CM, et al. Imipramine-induced hyperpigmentation: four cases and a review of the literature. J Am Acad Dermatol 1999;40:159-66.

3. Atkin DH, Fitzpatrick RE. Laser treatment of imipramine-induced hyperpigmentation. J Am Acad Dermatol 2000;43:77-80.

4. Izikson L, Anderson RR. Delayed darkening of imipramineinduced hyperpigmentation after treatment with a Q-switched Nd:YAG laser followed by a Q-switched ruby laser. Dermatol Surg 2009;35:527-9.

5. Alster TS, Gupta SN. Minocycline-induced hyperpigmentation treated with a 755-nm Q-switched alexandrite laser. Dermatol Surg 2004;30:1201-4.
6. Wiper A, Roberts DH, Schmitt M. Amiodarone-induced skin pigmentation: Q-switched laser therapy, an effective treatment option. Heart 2007;93:15.

7. Wee SA, Dover JS. Effective treatment of psychotropic druginduced facial hyperpigmentation with a 755 -nm Q-switched alexandrite laser. Dermatol Surg 2008;34:1609-12.

Address correspondence and reprint requests to: Jeffrey $S$. Orringer, MD, Department of Dermatology, University of Michigan Medical School, 1500 E. Medical Center Drive, 1910 Taubman Center, Ann Arbor, Michigan 48109, or e-mail: jorringe@umich.edu 